\title{
Missed opportunities for family planning counselling among postpartum women in eleven counties in Kenya
}

Mary N. Thiongo ${ }^{1 \dagger}$, Peter B. Gichangi ${ }^{2^{*}+}$, Michael Waithaka' ${ }^{1}$ Amy Tsui ${ }^{3}$, Linnea A. Zimmerman ${ }^{3}$, Scott Radloff ${ }^{3}$, Marleen Temmerman ${ }^{4}$ and Saifuddin Ahmed $^{3}$

\begin{abstract}
Background: Mothers may access medical facilities for their babies and miss opportunities to access family planning (FP) services. This study was undertaken to describe missed opportunities for FP among women within the extended (0-11 months) postpartum period from counties participating in Performance Monitoring and Accountability 2020 (PMA2020) surveys.
\end{abstract}

Design and setting: This study analysed cross-sectional household survey data from 11 counties in Kenya between 2014 and 2018. PMA2020 uses questions extracted from the Demographic and Health survey (DHS) and DHS definitions were used. Multivariable logistic regression was used for inferential statistics with $p$-value of $<0.05$ considered to be significant.

Participants: Women aged 15-49years from the households visited.

Primary outcome measure: Missed opportunity for family planning/contraceptives (FP/C) counselling.

Results: Of the 34,832 women aged 15-49years interviewed, 10.9\% (3803) and 10.8\% (3746) were in the period 0-11 months and 12-23 months postpartum respectively, of whom, 38.8 and $39.6 \%$ respectively had their previous pregnancy unintended. Overall, $50.4 \%$ of women $0-23$ months postpartum had missed opportunities for FP/C counselling. Among women who had contact with health care at the facility, 39.2\% of women 0-11 months and $44.7 \%$ of women 12-23 months had missed opportunities for FP/C counselling. Less than half of the women 0-11 months postpartum (46.5\%) and $64.5 \%$ of women $12-23$ months postpartum were using highly efficacious methods. About 27 and 18\% of the women 0-11 months and $12-23$ months postpartum respectively had unmet need for FP/C. Multivariable analysis showed that being low parity and being from the low wealth quintile significantly increased the odds of missed opportunities for FP/C counselling among women in the extended postpartum period, $p<0.05$.

Conclusions: A large proportion of women have missed opportunities for FP/C counselling within 2 years postpartum. Programs should address these missed opportunities.

Keywords: Contraception, Family Planning, Maternal health service integration, Missed opportunity, mCPR, Unmet need, Kenya

*Correspondence: gichangip2015@gmail.com

${ }^{\dagger}$ Mary N. Thiongo and Peter B. Gichangi have equal contribution.

${ }^{2}$ Technical University of Mombasa, Mombasa, Kenya

Full list of author information is available at the end of the article

\section{Introduction}

Universal access to reproductive health is essential to achieve the Sustainable Development Goals (SDGs) on health $[1,2]$. The benefits of family planning, including reduction of maternal death, delaying motherhood, 
avoiding unintended pregnancies and abortions and reduction of mother to child transmission of HIV, accrue to women themselves, their offspring [3], and society [4-6]. Some of those benefits result from increasing the proportion of births that are optimally spaced $[7,8]$. The recommended "birth-to-pregnancy interval" or "interpregnancy interval," which is the duration between two consecutive pregnancies [7, 9], is considered to be at least 24 months. There is an increase in maternal, newborn, and child morbidity and in early childhood mortality rates associated with shorter intervals, particularly those less than 18 months [10-13]. Lack of access and use of family planning/contraceptives $(\mathrm{FP} / \mathrm{C})$ in the postpartum period often lead to short birth intervals. Provision of quality $\mathrm{FP} / \mathrm{C}$ services in the postpartum period has the potential to reduce both maternal and childhood mortality and morbidity arising from unsafe abortions and inadequate spacing of births, respectively [14-17]. Postpartum $\mathrm{FP} / \mathrm{C}$ is a proxy marker for integration and quality of FP services $[17,18]$.

While the clinical definition of the "postpartum" period is 42 days after birth, many programs are adopting the extended-postpartum to extend traditional postpartum period up to 1 year after birth $[12,14,18]$. Extended postpartum period is critical in preventing pregnancies and their associated complications. There are several safe and effective FP/C methods that women can use at various points after delivery, such as postpartum intrauterine devices, sterilization (male and female), condoms and emergency contraception, to optimize birth spacing and limiting $[15,18]$.

The postpartum period offers multiple opportunities for healthcare providers to assess, provide or promote $\mathrm{FP} / \mathrm{C}$. In 2014 , about $61 \%$ of all women $15-49$ years in Kenya delivered in a health facility, $51 \%$ of mothers made a postpartum visit and $79 \%$ of the children $12-23$ months received basic vaccines [19] indicating substantial number of women of reproductive age had the potential to access to services in the postpartum period.

These maternal and newborn health services utilizations are opportunities for women to receive $\mathrm{FP} / \mathrm{C}$ services during the extended postpartum period [17, $18,20,21]$. A study on integration of FP into non-FP services [22] and postpartum FP with maternal, newborn and child health services [23] found that integration can reduce unmet need and increase uptake of FP/C services. The estimated prospective postpartum unmet for FP/C among postpartum women within 23 months post-delivery in Kenya is 57\% [24]. There is need therefore to study $\mathrm{FP} / \mathrm{C}$ use and its determinants among women of reproductive age in Kenya. Performance Monitoring and Accountability 2020 (PMA2020), designed to track performance of Family
Planning 2020 (FP2020) commitments by different partners, generates $\mathrm{FP} / \mathrm{C}$ data from households in 11 counties in Kenya. In this paper, we report missed opportunities for FP/C counselling among women within the extended ( $0-11$ months) postpartum period and women 12-23 months post-delivery from a nationally representative counties participating in PMA2020 surveys.

\section{Materials and methods}

\section{Data source}

Nationally representative data collected via Performance Monitoring and Accountability 2020 (PMA2020) surveys in Kenya from 2014 to 2018 was used. PMA2020 conducts surveys every 6 months to 1 year, providing Family Planning 2020 (FP2020), governments, and other stakeholders' frequent information on contraceptive use, demand, and supply that can inform policies and programs and identify areas for improvement. For each round of data collection, a new sample of households is chosen. The EAs were refreshed in 2016 and maintained till 2018. The PMA2020 household and female survey uses a two-stage cluster sample design with residential area (urban and rural) and county as strata to draw a probability sample of households and eligible females (age 15-49 years) across eleven counties in Kenya. In the first stage of sampling eleven of Kenya's 47 counties were selected, using probability proportional to size procedures. Within the counties, clusters or enumeration areas (EAs) were selected proportional to size with urban/rural stratification. The sample of EAs was powered to generate national and urban/rural estimates of all woman modern contraceptive prevalence rates (mCPR) with less than $3 \%$ margin of error. A comprehensive description of the survey design is detailed elsewhere [25]. All study procedures were performed as per the research guidelines and regulations by the Kenyatta National Hospital and University of Nairobi Ethics review committee and National Council for Science, Technology and Innovation.

\section{Study population}

We analysed a subsample of women aged $15-49$ years who had a birth in the last $0-11$ months, i.e., women in the extended postpartum period [12, 14, 18] and the results were compared to those for women $12-23$ months post-delivery. Since pregnancy is possible within the first 6 months postpartum and some have experienced menses return within the period [26], the extended postpartum period was further divided into two sub periods: $0-5$ months, $6-11$ months in some analyses. 


\section{Study variables \\ Dependent variables}

The main outcome of interest was missed opportunity for $\mathrm{FP} / \mathrm{C}$ counselling at the health facility or both at the facility and at the community. A missed opportunity for FP/C counselling at the facility refers to any contact with a health care worker at the facility by a woman in the postpartum period, which does not result in the person being counselled on $\mathrm{FP} / \mathrm{C}$. The overall missed opportunity for $\mathrm{FP} / \mathrm{C}$ counselling refers to no counselling at all on $\mathrm{FP} / \mathrm{C}$ either at the facility (for postpartum women who visited a facility in the last 12 months) and at the community (for postpartum women who visited a health facility in the last 12 months and were not counselled on $\mathrm{FP} / \mathrm{C}$ as well as those who had not visited a health facility in the last 12 months and were not reached for $\mathrm{FP} / \mathrm{C}$ counselling at the community by health care workers. A flow diagram representing the definition is shown in the supplemental material Fig. 1 and Fig. 2. Other variables that were assessed include demand for $\mathrm{FP} / \mathrm{C}, \mathrm{FP} / \mathrm{C}$ use and unmet need for FP/C among postpartum women. Family planning/contraceptive use include the use of modern (Intrauterine devices (IUDs), hormone implants, male and female sterilizations, injectables, contraceptive pills, condoms, diaphragms, spermicidal agents and emergency contraception) as well as traditional (periodic abstinence, withdrawal and other folkloric methods) FP/C methods. Unmet need for $\mathrm{FP} / \mathrm{C}$ was defined as the percentage of fertile, sexually active women ages $15-49$ who were not using contraception and did not wish to become pregnant at all (unmet need for limiting) or within the next 2 years (unmet need for spacing)). Women were considered to have a demand for $\mathrm{FP} / \mathrm{C}$ if they wanted to delay, space or limit childbearing.

\section{Independent variables}

Analyses in this study were stratified by woman's age (15-19, 20-24, 25-29, 30-34, 35-39, 40-44, 45-49years); wealth quintiles, based on the asset index included in the national survey datasets (lowest, lower, middle, higher and the highest wealth quintiles); marital status (never married, married or in union, widowed/divorced/separated); level of education (none, primary, technical/vocational, secondary or higher); area of residence (urban or rural) and parity (No children, 1 or 2 children, 3 or 4 children, 5 or more children). Other important covariates considered in this analysis include county of residence and round of data collection.

\section{Data analysis}

Descriptive statistics including percentage, means, medians and standard deviation were computed. Means were compared using t-tests while Chi-square tests were used to measure the association between the factors and outcome variables. To study the covariates of missed opportunity for $\mathrm{FP} / \mathrm{C}$, bivariate and multivariable logistic regressionanalysis was applied using enter method to calculate the odds ratio (OR) and adjusted oddsratio (aOR) of missed opportunity for FP/C. The complex survey design and weights (individual sampling weights for women) were taken into account during the analysis. STATA 15.0 statistical software was used for all analyses (Stata Corporation, College Station, TX, USA). $P<0.05$ was considered significant.

\section{Results}

From 2014 to 2018, a total of 34,832 women aged $15-49$ years were interviewed. The response rate was between 97.0 and $99.0 \%$ for all the rounds. Table 1 shows the sociodemographic characteristics of all women who participated in the PMA surveys as well as women 0-11 and 12-23 months post-delivery. Overall, the majority $(58.4 \%)$ of the respondents were between the ages 15 and 29 years. About a third (31.9\%) had never been married, $64.6 \%$ were from rural areas while $4.3 \%$ had no formal education. About a third of the respondents had one to two children (33.6\%) and the majority were sexually active (58.0\%). About a third of the respondents were from high (higher/highest) wealth quintile (37.9\%) (Table 1). Out of the 34,832 women who had participated in the seven rounds of PMA2020 data collection 3803 (10.9\%) and $3746(10.8 \%)$ were 0 - 11 months and 12 23 months post-delivery respectively. Among women 0 11 months and $12-23$ months post-delivery, the majority were between the ages $20-24$ years, were married or in a union, were from rural residence, had primary level education, were from the lowest wealth quintile, had one or two previous births, were sexually active and were residing in Nairobi County.

Among women $0-11$ months and $12-23$ months post-delivery, 0.5 and $4.6 \%$ were pregnant respectively at the time of the survey (Table 2). Among women within 2 years post-delivery, $69.1 \%$ were sexually active at the time of the survey (Table 2). Of all the pregnancies at the time of the survey, 23.8 and $57.4 \%$ among women 0 - 11 and 12-23 months post-delivery respectively were unintended (wanted later or not at all). Among the sexually active women, 38.8 and $39.6 \%$ of those $0-11$ months postpartum and 12-23 months postpartum respectively had a previous unintended pregnancy. About $2.1 \%$ of sexually active women within the 12-month postpartum period and $3.8 \%$ of sexually active women $12-23$ months post-delivery expressed a desire to have another pregnancy within 2 years (Table 2 ). 
Table 1 Sociodemographic characteristics of all women, women 0-11 and 12-23 months post-delivery

\begin{tabular}{|c|c|c|c|c|c|c|c|c|c|}
\hline \multirow[t]{2}{*}{ Characteristic } & \multicolumn{3}{|c|}{ All women $(N=34,832)$} & \multicolumn{3}{|c|}{$\begin{array}{l}\text { Women } 0-11 \text { months postpartum } \\
(N=3803)\end{array}$} & \multicolumn{3}{|c|}{$\begin{array}{l}\text { Women } 11-23 \text { months } \\
\text { postpartum }(N=3746)\end{array}$} \\
\hline & $\mathbf{N}$ & $\mathrm{N}^{*}$ & $\%$ & $N$ & $\mathrm{~N}^{*}$ & $\%$ & $\mathrm{~N}$ & $\mathrm{~N}^{*}$ & $\%$ \\
\hline \multicolumn{10}{|l|}{ Age group } \\
\hline $15-19$ & 6973 & 6833 & 19.6 & 455 & 453 & 11.9 & 281 & 273 & 7.3 \\
\hline $20-24$ & 6599 & 6799 & 19.5 & 1267 & 1306 & 34.4 & 1139 & 1147 & 30.6 \\
\hline $25-29$ & 6496 & 6719 & 19.3 & 1058 & 1075 & 28.3 & 1099 & 1135 & 30.3 \\
\hline $30-34$ & 5159 & 5172 & 14.9 & 629 & 608 & 16.0 & 710 & 705 & 18.8 \\
\hline $35-39$ & 4034 & 3842 & 11.0 & 288 & 268 & 7.0 & 355 & 337 & 9.0 \\
\hline $40-45$ & 3209 & 3160 & 9.1 & 88 & 76 & 2.0 & 122 & 113 & 3.0 \\
\hline $45-49$ & 2362 & 2306 & 6.6 & 18 & 16 & 0.4 & 40 & 35 & 0.9 \\
\hline \multicolumn{10}{|l|}{ Marital Status } \\
\hline Never Married & 11,093 & 11,127 & 31.9 & 540 & 571 & 15.0 & 410 & 437 & 11.7 \\
\hline Married/In a union & 21,123 & 21,104 & 60.6 & 3141 & 3119 & 82.0 & 3137 & 3105 & 82.9 \\
\hline Widowed/Divorced & 2591 & 2570 & 7.4 & 120 & 109 & 2.9 & 197 & 203 & 5.4 \\
\hline Missing/No response & 25 & 31 & 0.1 & 2 & 4 & 0.1 & 2 & 1 & 0.0 \\
\hline \multicolumn{10}{|l|}{ Residence } \\
\hline Rural & 22,138 & 22,507 & 64.6 & 2545 & 2513 & 66.1 & 2513 & 2499 & 66.7 \\
\hline Urban & 12,694 & 12,325 & 35.4 & 1258 & 1290 & 33.9 & 1233 & 1247 & 33.3 \\
\hline \multicolumn{10}{|l|}{ Education } \\
\hline No Education & 1706 & 1481 & 4.3 & 290 & 233 & 6.1 & 282 & 232 & 6.2 \\
\hline Primary & 16,928 & 16,700 & 47.9 & 1979 & 1941 & 51.0 & 1998 & 1959 & 52.3 \\
\hline Technical/Nocational & 710 & 689 & 2.0 & 89 & 85 & 2.2 & 85 & 74 & 2.0 \\
\hline Secondary & 10,973 & 11,226 & 32.2 & 1000 & 1042 & 27.4 & 952 & 1008 & 26.9 \\
\hline Higher & 4509 & 4728 & 13.6 & 445 & 503 & 13.2 & 429 & 473 & 12.6 \\
\hline Missing/No response & 6 & 8 & 0.0 & 0 & 0 & 0.0 & 0 & 0 & 0.0 \\
\hline \multicolumn{10}{|l|}{ Wealth Quintile } \\
\hline Lowest & 7820 & 7299 & 21.0 & 1074 & 984 & 25.9 & 1050 & 954 & 25.5 \\
\hline Lower & 7549 & 7389 & 21.2 & 885 & 861 & 22.7 & 891 & 868 & 23.2 \\
\hline Middle & 6991 & 6951 & 20.0 & 741 & 727 & 19.1 & 686 & 693 & 18.5 \\
\hline Higher & 6337 & 6285 & 18.0 & 593 & 609 & 16.0 & 616 & 609 & 16.3 \\
\hline Highest & 6135 & 6908 & 19.8 & 510 & 622 & 16.4 & 503 & 622 & 16.6 \\
\hline \multicolumn{10}{|l|}{ Parity } \\
\hline None & 9758 & 9691 & 27.8 & $\mathrm{~N} / \mathrm{A}$ & N/A & & $\mathrm{N} / \mathrm{A}$ & $\mathrm{N} / \mathrm{A}$ & \\
\hline $1-2$ & 11,333 & 11,694 & 33.6 & 2104 & 2188 & 57.5 & 2005 & 2058 & 54.9 \\
\hline $3-4$ & 8009 & 7832 & 22.5 & 1021 & 992 & 26.1 & 1032 & 1030 & 27.5 \\
\hline $5+$ & 5732 & 5615 & 16.1 & 678 & 623 & 16.4 & 709 & 658 & 17.6 \\
\hline \multicolumn{10}{|l|}{ Sexually active } \\
\hline No & 14,346 & 14,616 & 42.0 & 1356 & 1407 & 37.0 & 800 & 834 & 22.3 \\
\hline Yes & 20,486 & 20,216 & 58.0 & 2447 & 2396 & 63.0 & 2946 & 2912 & 77.7 \\
\hline \multicolumn{10}{|l|}{ Ever given birth } \\
\hline No & 9708 & 9632 & 27.7 & $\mathrm{~N} / \mathrm{A}$ & N/A & & $\mathrm{N} / \mathrm{A}$ & $\mathrm{N} / \mathrm{A}$ & \\
\hline Yes & 25,074 & 25,141 & 72.2 & 3803 & 3803 & 100.0 & 3746 & 3746 & 100.0 \\
\hline Missing/No response & 50 & 59 & 0.2 & & 0 & 0.0 & 0 & 0 & 0.0 \\
\hline \multicolumn{10}{|l|}{ Data collection round } \\
\hline Jun/Jul 2014 & 3754 & 3729 & 10.7 & 461 & 454 & 11.9 & 476 & 458 & 12.2 \\
\hline Nov/Dec 2014 & 4329 & 4324 & 12.4 & 487 & 493 & 13.0 & 472 & 462 & 12.3 \\
\hline Jun/Jul 2015 & 4396 & 4385 & 12.6 & 528 & 541 & 14.2 & 449 & 458 & 12.2 \\
\hline Nov/Dec 2015 & 4921 & 4895 & 14.1 & 492 & 525 & 13.8 & 509 & 538 & 14.4 \\
\hline Nov/Dec 2016 & 5885 & 5916 & 17.0 & 645 & 627 & 16.5 & 647 & 642 & 17.1 \\
\hline
\end{tabular}


Table 1 (continued)

\begin{tabular}{|c|c|c|c|c|c|c|c|c|c|}
\hline \multirow[t]{2}{*}{ Characteristic } & \multicolumn{3}{|c|}{ All women $(N=34,832)$} & \multicolumn{3}{|c|}{$\begin{array}{l}\text { Women } 0-11 \text { months postpartum } \\
(N=3803)\end{array}$} & \multicolumn{3}{|c|}{$\begin{array}{l}\text { Women } 11-23 \text { months } \\
\text { postpartum }(N=3746)\end{array}$} \\
\hline & $\mathrm{N}$ & $\mathrm{N}^{*}$ & $\%$ & $\mathrm{~N}$ & $\mathrm{~N}^{*}$ & $\%$ & $\mathrm{~N}$ & $\mathrm{~N}^{*}$ & $\%$ \\
\hline Nov/Dec 2017 & 5876 & 5895 & 16.9 & 575 & 581 & 15.3 & 602 & 590 & 15.7 \\
\hline Nov/Dec 2018 & 5671 & 5688 & 16.3 & 615 & 583 & 15.3 & 591 & 599 & 16.0 \\
\hline \multicolumn{10}{|l|}{ County } \\
\hline Bungoma & 3954 & 3039 & 8.7 & 433 & 332 & 8.7 & 461 & 361 & 361 \\
\hline Kakamega & 1513 & 3033 & 8.7 & 150 & 293 & 7.7 & 149 & 296 & 296 \\
\hline Kericho & 3691 & 3955 & 11.4 & 411 & 437 & 11.5 & 405 & 431 & 431 \\
\hline Kiambu & 3212 & 3166 & 9.1 & 267 & 295 & 7.8 & 254 & 269 & 269 \\
\hline Kilifi & 4069 & 3721 & 10.7 & 522 & 501 & 13.2 & 517 & 479 & 479 \\
\hline Kitui & 3634 & 3396 & 9.8 & 300 & 266 & 7.0 & 365 & 333 & 333 \\
\hline Nairobi & 3258 & 4930 & 14.2 & 360 & 567 & 14.9 & 322 & 518 & 518 \\
\hline Nandi & 3816 & 3283 & 9.4 & 370 & 321 & 8.5 & 348 & 292 & 292 \\
\hline Nyamira & 3317 & 2459 & 7.1 & 327 & 244 & 6.4 & 291 & 220 & 220 \\
\hline Siaya & 2959 & 2902 & 8.3 & 393 & 374 & 9.8 & 381 & 378 & 378 \\
\hline \multirow[t]{2}{*}{ West Pokot } & 1409 & 949 & 2.7 & 270 & 173 & 4.6 & 253 & 168 & 168 \\
\hline & Mean (S.D.) & & Median & Mean (S.D.) & & Median & Mean (S.D.) & & Median \\
\hline Age of the participants & $28.5(9.2)$ & & 27.0 & $25.9(5.8)$ & & 25.0 & $27.1(6.1)$ & & 26.0 \\
\hline Number of live births & $2.6(2.3)$ & & 2.0 & $2.7(1.9)$ & & 2.0 & $2.8(2.0)$ & & 2.0 \\
\hline Age at first birth & $20.0(3.7)$ & & 19.6 & $20.1(3.7)$ & & 19.6 & $20.1(3.9)$ & & 19.6 \\
\hline Age at first sex & $17.5(3.1)$ & & 17.0 & $17.5(2.9)$ & & 17.0 & $17.4(3.1)$ & & 17.0 \\
\hline Age at first use of FP & $23.2(5.6)$ & & 22.0 & $22.2(4.5)$ & & 21.0 & $22.7(4.8)$ & & 22.0 \\
\hline
\end{tabular}

N Unweighted sample size, $N^{*}$ Weighted sample size, \% Weighted sample proportion, S.D. Standard deviation

Table 2 Pregnancy risk and fertility desire among the 24,968 women who had ever given birth before

\begin{tabular}{|c|c|c|c|c|c|c|}
\hline & \multicolumn{3}{|c|}{0 - 11 months (extended postpartum) $(\mathrm{N}=3803)$} & \multicolumn{3}{|c|}{$12-23$ month since last birth $(N=3746)$} \\
\hline & $\mathbf{N}$ & $\mathbf{N}^{*}$ & $\%$ & $\mathbf{N}$ & $\mathrm{N}^{*}$ & $\%$ \\
\hline Currently pregnant & 19 & 19 & 0.5 & 181 & 172 & 4.6 \\
\hline \multicolumn{7}{|l|}{ Current pregnancy unintended } \\
\hline Wanted later & 3 & 3 & 15.0 & 69 & 63 & 36.8 \\
\hline Not wanted at all & 2 & 2 & 8.8 & 37 & 36 & 20.6 \\
\hline Sexually active ${ }^{a}$ & 2447 & 2414 & 63.0 & 2946 & 2916 & 77.7 \\
\hline \multicolumn{7}{|c|}{ Previous unintended pregnancies among sexually active women } \\
\hline Wanted later & 691 & 690 & 28.1 & 873 & 883 & 29.8 \\
\hline Not wanted at all & 259 & 262 & 10.7 & 281 & 292 & 9.8 \\
\hline \multicolumn{7}{|c|}{ Desired waiting period till next birth (among sexually active women) } \\
\hline$<12$ months & 61 & 52 & 2.1 & 116 & 112 & 3.8 \\
\hline $12-23$ months & 66 & 50 & 2.0 & 109 & 88 & 3.0 \\
\hline 24-47 months & 549 & 528 & 21.5 & 611 & 577 & 19.5 \\
\hline $48+$ months & 768 & 840 & 34.2 & 815 & 874 & 29.5 \\
\hline Infertile/want no more/others & 1003 & 986 & 40.2 & 1295 & 1314 & 44.3 \\
\hline
\end{tabular}

$N$ Unweighted sample size, $N^{*}$ Weighted sample size, \% Weighted sample proportion, ${ }^{a}$ sexually active women are those who reported to had sex in the last 30 days at the time of the survey

Figure 1 and supplemental material Table 1 presents missed opportunity for FP/C counselling, contraceptive use and unmet need for family planning among women in the period $0-11$ months and $12-23$ months post-delivery. Missed opportunity for FP/C counselling increased with increasing duration post-delivery from 

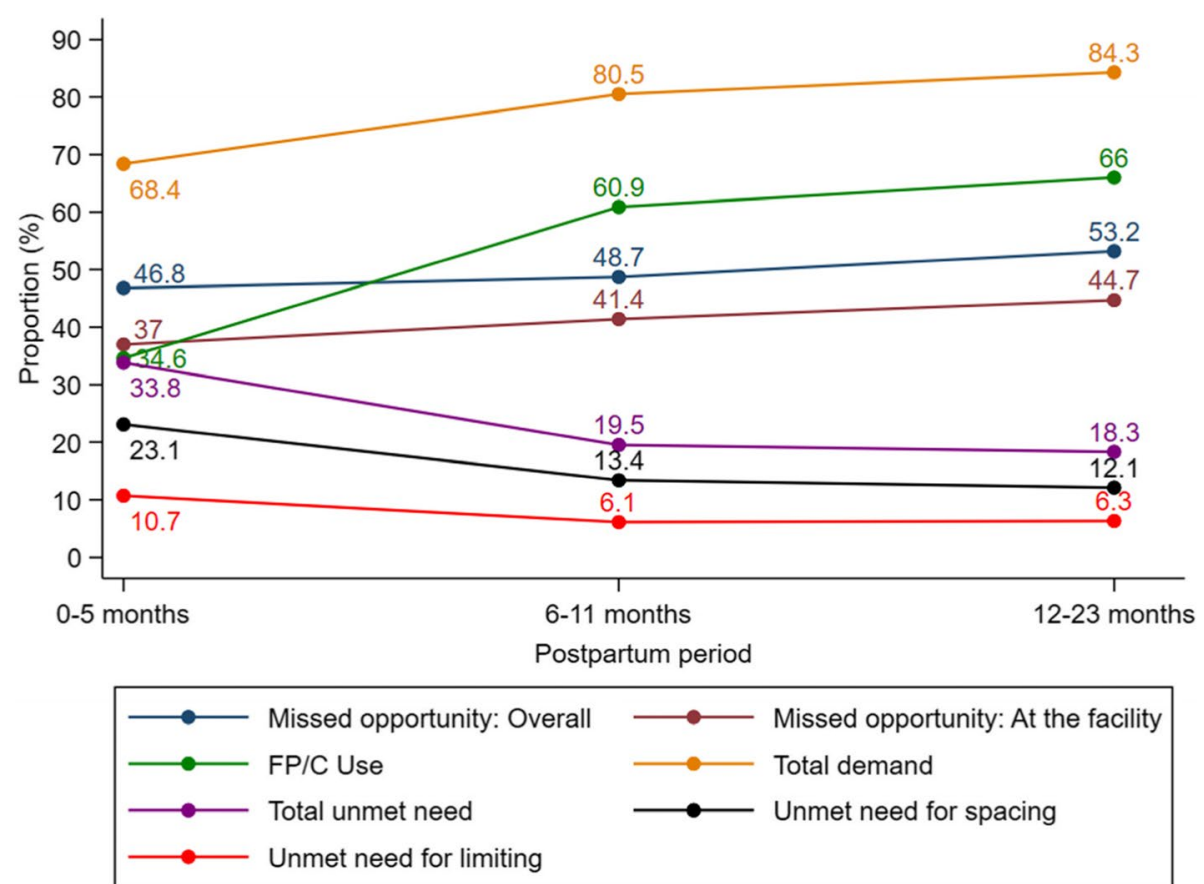

Fig. 1 Missed opportunity, modern family planning/contraceptive (FP/C) use and Unmet need for family planning

$46.8 \%$ at $0-5$ months to $53.2 \%$ at $12-23$ months postdelivery (both at the facility and at the community level). The overall missed opportunity for $\mathrm{FP} / \mathrm{C}$ counselling among women $12-23$ months post-delivery $(53.2 \%)$ was significantly higher than among women in the extended postpartum period $(47.7 \%), p=0.001$. At the health facilities, about $37.0,41.4$ and $44.7 \%$ of the women $0-$ 5 months, $6-11$ months and $12-23$ months post-delivery had missed opportunity for $\mathrm{FP} / \mathrm{C}$ respectively. Missed opportunity for $\mathrm{FP} / \mathrm{C}$ counselling at the health facilities among women $12-23$ months post-delivery (44.7\%) was significantly higher than among women in the extended postpartum period (39.2\%), $p=0.003$. Family planning/ contraceptive use increases with increase in the duration post-delivery, while unmet need for $\mathrm{FP} / \mathrm{C}$ decreases with increase in the duration post-delivery. Total demand for $\mathrm{FP} / \mathrm{C}$ also increased with increase in the duration postdelivery, Fig. 1.

Table 3 shows bivariate analysis of current FP/C use and intendedness of last pregnancy among sexually active women. There is no significant association between the overall missed opportunity for $\mathrm{FP} / \mathrm{C}$ counselling and

Table 3 Association between missed opportunity, FP/C use, intendedness of last pregnancy and unmet need

\begin{tabular}{|c|c|c|c|c|c|c|}
\hline & \multicolumn{3}{|c|}{0 - 11 months (extended postpartum) $\mathrm{N}=3803$} & \multicolumn{3}{|c|}{$\begin{array}{l}12-23 \text { month since last birth } \\
N=3746\end{array}$} \\
\hline & n (\%) & OR $(95 \% \mathrm{Cl})$ & $p$-value & n (\%) & OR $(95 \% \mathrm{Cl})$ & $p$-value \\
\hline \multicolumn{7}{|c|}{ Modern contraceptive use } \\
\hline Non users & $997(48.7)$ & Ref. & & $760(57.1)$ & & \\
\hline Users & $829(46.7)$ & $0.92(0.79,1.08)$ & 0.323 & $1233(51.0)$ & $0.78(0.65,0.94)$ & 0.007 \\
\hline \multicolumn{7}{|c|}{ Last pregnancy intendedness } \\
\hline Intended & $1037(48.0)$ & Ref. & & $1178(54.4)$ & Ref. & \\
\hline Unintended & $789(47.4)$ & $0.97(0.82,1.15)$ & 0.753 & $815(51.5)$ & $0.89(0.75,1.06)$ & 0.179 \\
\hline \multicolumn{7}{|l|}{ Total unmet need } \\
\hline No unmet need & $1301(46.9)$ & Ref. & & $1596(52.6)$ & Ref. & \\
\hline Unmet need & $496(48.8)$ & $1.08(0.90,1.29)$ & 0.411 & $383(55.8)$ & $1.14(0.92,1.41)$ & 0.120 \\
\hline
\end{tabular}

$n$ Weighted sample with missed opportunity in the subgroup, \% Weighted sample proportion, OR Crude Odds Ratio, CI Confidence Interval 
modern contraceptive use among sexually active women in the extended postpartum period, $P>0.05$. On the contrary, among women in the $12-23$ months post-delivery period, there was a significant association between the overall missed opportunity for $\mathrm{FP} / \mathrm{C}$ counselling and modern contraceptive use among sexually active women, $p=0.007$. Missed opportunity for FP/C counselling was not significantly associated with the last birth being unintended among women in the extended postpartum period $(p=0.753)$ and among women $12-23$ months post-delivery $(p=0.179)$. Similarly, unmet need for FP/C counselling was not significantly associated with missed opportunity for $\mathrm{FP} / \mathrm{C}$ counselling among women in the extended postpartum period $(p=0.411)$ and among women $12-23$ months post-delivery $(p=0.120)$.

Results of the univariate and multivariable analysis of the correlates of the overall missed opportunity for FP/C counselling among women $0-11$ and 12-23 months postpartum are shown in Table 4. Bivariate analysis showed that rural/urban residence, education, wealth, parity, round of data collection and county of residence were all significant predictors of overall missed opportunity for $\mathrm{FP} / \mathrm{C}$ counselling among women in the extended postpartum period, $p<0.05$. When compared to urban residents, rural residents were more likely to have a missed opportunity for $\mathrm{FP} / \mathrm{C}$ counselling, $p=0.032$. Those with some level of formal education were less likely to have a missed opportunity for $\mathrm{FP} / \mathrm{C}$ counselling, when compared to the reference group of women with no education. Women in the higher wealth quintiles were less likely to have a missed opportunity for $\mathrm{FP} / \mathrm{C}$ counselling when compared to the reference group of women from the lowest wealth quintile. Those with $3-4$ past births were less likely to have a missed opportunity for $\mathrm{FP} / \mathrm{C}$ counselling when compared to the reference group of women with one or two past births. Women from Kericho, Nandi and West Pokot counties were more likely to have a missed opportunity for $\mathrm{FP} / \mathrm{C}$ counselling when compared to women from Bungoma county, Table 4.

As in bivariate analysis, age, marital status and sexual activity remained insignificant predictors of missed opportunity for $\mathrm{FP} / \mathrm{C}$ counselling in the adjusted analysis. After controlling for all variables statistically significant on bivariate analysis in Table 4, rural/urban residence and education were no longer significant predictors of missed opportunity for FP/C counselling. The likelihood of having a missed opportunity for FP/C counselling was almost two-times among those who had no education as compared to those who had higher education $(\mathrm{AOR}=1.96, p=0.006)$. Within the wealth quintile categories, the only significant finding was that women from the lower quintile were less likely $(\mathrm{AOR}=0.72, p=0.005$ ) to have a missed opportunity for $\mathrm{FP} / \mathrm{C}$ counselling when compared to women in the lowest wealth quintile. Women with three to four past births were less likely to have a missed opportunity for $\mathrm{FP} / \mathrm{C}$ counselling (AOR: 0.73, 95\% CI: $0.58,0.92, p=0.009$ ) when compared to the reference group of women with one or two past births. By county of residence, women from Kericho, Nandi and West Pokot counties were more likely to have a missed opportunity for $\mathrm{FP} / \mathrm{C}$ counselling when compared to women from Bungoma county, $p<0.05$. Round of data collection and county of residence were the only significant predictors of overall missed opportunity for $\mathrm{FP} / \mathrm{C}$ counselling among women in the period $12-23$ months post-delivery, $p<0.05$.

Bivariate and multivariable analysis results for missed opportunity for FP/C at the facility are shown in Table 5. Parity, round of data collection and county of residence were the significant covariates of missed opportunity for $\mathrm{FP} / \mathrm{C}$ counselling at the facility among women in the extended postpartum period. Women who had three to four previous births (adjusted OR: 0.71, $p=0.009$ ) were less likely to have a missed opportunity for $\mathrm{FP} / \mathrm{C}$ counselling at the facility when compared to women with one or two past births. By county of residence, women from Kericho, Nandi and West Pokot counties were 2-3 times more likely to have a missed opportunity for FP/C counselling at the facility when compared to women from Bungoma county, $p<0.05$. Round of data collection and county of residence were the only significant predictors of overall missed opportunity for $\mathrm{FP} / \mathrm{C}$ counselling at the facility among women in the period $12-23$ months post-delivery, $p<0.05$. Women from Kericho, Kilifi, Nairobi, Nandi and West Pokot counties were more likely to have a missed opportunity for $\mathrm{FP} / \mathrm{C}$ counselling at the facility when compared to women from Bungoma county, $p<0.05$.

\section{Discussion}

Our data show that among women in the extended postpartum period of 0-11 months, more than half were sexually active, had low FP/C use, had high unmet need, high demand for FP and most had experienced unintended pregnancies in the past. Though Kenya has made tremendous progress at the national level to increase $\mathrm{mCPR}$ from 39.4 in $2008 / 9$ to $53.2 \%$ in 2014 [19] and to $60.8 \%$ in 2018 [27], there are missed opportunities for FP/C services which if addressed, could increase $\mathrm{mCPR}$ further. For women 0-23 months postdelivery who made contact with health care workers or were visited by community health workers (CHWs), those with missed opportunities for $\mathrm{FP} / \mathrm{C}$ counselling increased from $47.7 \%$ for those $0-11$ months to $53.2 \%$ for those $12-23$ months. Other studies on postpartum FP have documented similar missed opportunities [18, 24]. The World Health 
Table 4 Bivariate and multivariate analysis of overall (facility and community health worker) missed FP/C opportunity among women in the 0-11 months and 12-23 months postpartum periods

\begin{tabular}{|c|c|c|c|c|c|c|c|c|}
\hline \multirow[t]{3}{*}{ Characteristic } & \multicolumn{4}{|c|}{0 - 11 months (extended postpartum) $-\mathrm{N}=3803$} & \multicolumn{4}{|c|}{12 - 23 month since last birth $-N=3746$} \\
\hline & \multicolumn{2}{|l|}{ Bivariate analysis } & \multicolumn{2}{|c|}{ Multivariable analysis } & \multicolumn{2}{|l|}{ Bivariate analysis } & \multicolumn{2}{|c|}{ Multivariable analysis } \\
\hline & Odds Ratio $(95 \% \mathrm{Cl})$ & $p$-value & $\begin{array}{l}\text { Adjusted Odds } \\
\text { Ratio }(95 \% \mathrm{Cl})\end{array}$ & $p$-value* & Odds Ratio $(95 \% \mathrm{Cl})$ & $p$-value & $\begin{array}{l}\text { Adjusted Odds } \\
\text { Ratio }(95 \% \mathrm{Cl})\end{array}$ & $p$-value* \\
\hline \multicolumn{9}{|l|}{ Age group } \\
\hline $15-19$ & Ref. & 0.345 & Ref. & 0.488 & Ref. & 0.414 & Ref. & 0.772 \\
\hline $20-24$ & $0.99(0.77,1.27)$ & & $1.10(0.83,1.46)$ & & $0.98(0.72,1.32)$ & & $1.04(0.75,1.44)$ & \\
\hline $25-29$ & $0.82(0.63,1.06)$ & & $0.95(0.69,1.30)$ & & $0.87(0.65,1.17)$ & & $0.97(0.68,1.36)$ & \\
\hline $30-34$ & $0.94(0.71,1.25)$ & & $1.13(0.79,1.62)$ & & $0.83(0.6,1.15)$ & & $0.93(0.62,1.39)$ & \\
\hline $35-39$ & $0.79(0.56,1.13)$ & & $0.92(0.60,1.42)$ & & $0.93(0.65,1.32)$ & & $0.98(0.62,1.54)$ & \\
\hline $40-45$ & $0.74(0.45,1.21)$ & & $0.79(0.44,1.40)$ & & $1.30(0.78,2.16)$ & & $1.34(0.75,2.37)$ & \\
\hline $45-49$ & $0.79(0.29,2.19)$ & & $0.72(0.26,2.01)$ & & $0.83(0.41,1.67)$ & & $0.75(0.35,1.63)$ & \\
\hline \multicolumn{9}{|l|}{ Marital Status } \\
\hline Never Married & Ref. & 0.150 & Ref. & 0.546 & Ref. & 0.027 & Ref. & 0.073 \\
\hline Married/In a union & $0.81(0.66,1.00)$ & & $0.90(0.69,1.17)$ & & $0.79(0.63,1.00)$ & & $0.77(0.58,1.03)$ & \\
\hline Widowed/Divorced & $0.87(0.56,1.37)$ & & $1.06(0.65,1.73)$ & & $1.12(0.76,1.66)$ & & $1.09(0.72,1.66)$ & \\
\hline \multicolumn{9}{|l|}{ Residence } \\
\hline Urban & Ref. & 0.032 & Ref. & 0.327 & Ref. & 0.230 & Ref. & 0.411 \\
\hline Rural & $1.27(1.02,1.57)^{*}$ & & $1.14(0.88,1.48)$ & & $0.87(0.70,1.09)$ & & $0.9(0.71,1.15)$ & \\
\hline \multicolumn{9}{|l|}{ Education } \\
\hline No Education & Ref. & 0.016 & Ref. & 0.086 & Ref. & 0.052 & Ref. & 0.138 \\
\hline Primary & $0.52(0.35,0.78)^{* *}$ & & $0.63(0.43,0.92)^{*}$ & & $0.60(0.41,0.88)^{*}$ & & $0.74(0.5,1.1)$ & \\
\hline $\begin{array}{l}\text { Technical/voca- } \\
\text { tional }\end{array}$ & $0.42(0.22,0.81)^{*}$ & & $0.56(0.29,1.09)$ & & $0.52(0.27,1.02)$ & & $0.64(0.32,1.29)$ & \\
\hline Secondary & $0.50(0.33,0.76)^{* *}$ & & $0.57(0.38,0.86)^{* *}$ & & $0.61(0.40,0.93)^{*}$ & & $0.69(0.44,1.07)$ & \\
\hline Higher & $0.46(0.29,0.72)^{* *}$ & & $0.51(0.31,0.83)^{* *}$ & & $0.50(0.32,0.79)^{* *}$ & & $0.56(0.35,0.88)^{*}$ & \\
\hline \multicolumn{9}{|l|}{ Wealth Quintile } \\
\hline Lowest & Ref. & 0.005 & Ref. & 0.023 & Ref. & 0.845 & Ref. & 0.962 \\
\hline Lower & $0.65(0.52,0.82)^{* *}$ & & $0.72(0.57,0.91)^{* *}$ & & $0.9(0.71,1.14)$ & & $1.01(0.8,1.28)$ & \\
\hline Middle & $0.69(0.53,0.89)^{* *}$ & & $0.88(0.67,1.15)$ & & $0.87(0.68,1.12)$ & & $0.96(0.74,1.26)$ & \\
\hline Higher & $0.70(0.53,0.91)^{* *}$ & & $0.98(0.71,1.35)$ & & $0.95(0.72,1.25)$ & & $0.91(0.67,1.25)$ & \\
\hline Highest & $0.67(0.49,0.92)^{*}$ & & $1.10(0.72,1.67)$ & & $0.91(0.64,1.29)$ & & $0.89(0.58,1.36)$ & \\
\hline \multicolumn{9}{|l|}{ Parity } \\
\hline $1-2$ & Ref. & 0.014 & Ref. & 0.026 & Ref. & 0.121 & Ref. & 0.410 \\
\hline $3-4$ & $0.76(0.64,0.92)^{* *}$ & & $0.73(0.58,0.92)^{* *}$ & & $0.85(0.71,1.01)$ & & $0.87(0.7,1.09)$ & \\
\hline $5+$ & $0.99(0.78,1.24)$ & & $0.86(0.62,1.19)$ & & $1.02(0.83,1.25)$ & & $0.96(0.71,1.29)$ & \\
\hline \multicolumn{9}{|l|}{ Sexually active } \\
\hline No & Ref. & 0.501 & Ref. & 0.866 & Ref. & 0.205 & Ref. & 0.515 \\
\hline Yes & $0.95(0.81,1.11)$ & & $1.02(0.85,1.21)$ & & $0.88(0.73,1.07)$ & & $1.08(0.85,1.37)$ & \\
\hline \multicolumn{9}{|l|}{ Data collection round } \\
\hline Jun/Jul 2014 & Ref. & 0.016 & Ref. & 0.003 & Ref. & 0.014 & Ref. & 0.017 \\
\hline Nov/Dec 2014 & $0.71(0.49,1.03)$ & & $0.69(0.47,1.01)$ & & $0.59(0.38,0.92)^{*}$ & & $0.6(0.39,0.93)^{*}$ & \\
\hline Jun/Jul 2015 & $1.00(0.70,1.42)$ & & $1.02(0.71,1.45)$ & & $0.55(0.37,0.82)^{* *}$ & & $0.54(0.36,0.81)^{* *}$ & \\
\hline Nov/Dec 2015 & $0.61(0.39,0.94)^{*}$ & & $0.60(0.38,0.93)^{*}$ & & $0.45(0.29,0.7)^{* *}$ & & $0.45(0.29,0.71)^{* *}$ & \\
\hline Nov/Dec 2016 & $0.83(0.60,1.16)$ & & $0.68(0.48,0.96)^{*}$ & & $0.71(0.48,1.04)$ & & $0.69(0.46,1.02)$ & \\
\hline Nov/Dec 2017 & $1.12(0.80,1.56)$ & & $0.95(0.66,1.36)$ & & $0.70(0.48,1.04)$ & & $0.66(0.44,0.99)^{*}$ & \\
\hline Nov/Dec 2018 & $0.68(0.48,0.96)^{*}$ & & $0.58(0.40,0.82)^{* *}$ & & $0.60(0.40,0.89)^{*}$ & & $0.56(0.37,0.85)^{* *}$ & \\
\hline
\end{tabular}


Table 4 (continued)

\begin{tabular}{|c|c|c|c|c|c|c|c|c|}
\hline \multirow[t]{3}{*}{ Characteristic } & \multicolumn{4}{|c|}{0 - 11 months (extended postpartum) $-\mathrm{N}=3803$} & \multicolumn{4}{|c|}{$12-23$ month since last birth $-N=3746$} \\
\hline & \multicolumn{2}{|l|}{ Bivariate analysis } & \multicolumn{2}{|c|}{ Multivariable analysis } & \multicolumn{2}{|l|}{ Bivariate analysis } & \multicolumn{2}{|c|}{ Multivariable analysis } \\
\hline & Odds Ratio $(95 \% \mathrm{Cl})$ & $p$-value & $\begin{array}{l}\text { Adjusted Odds } \\
\text { Ratio }(95 \% \mathrm{Cl})\end{array}$ & $p$-value* & Odds Ratio $(95 \% \mathrm{Cl})$ & $p$-value & $\begin{array}{l}\text { Adjusted Odds } \\
\text { Ratio }(95 \% \mathrm{Cl})\end{array}$ & $p$-value* \\
\hline \multicolumn{9}{|l|}{ County } \\
\hline Bungoma & Ref. & $<0.001$ & Ref. & $<0.001$ & Ref. & $<0.001$ & Ref. & $<0.001$ \\
\hline Kakamega & $1.35(0.79,2.32)$ & & $1.46(0.83,2.58)$ & & $1.35(0.83,2.18)$ & & $1.32(0.81,2.14)$ & \\
\hline Kericho & $1.5(1.01,2.22)^{*}$ & & $1.52(1.03,2.26)^{*}$ & & $1.72(1.15,2.57)^{* *}$ & & $1.75(1.18,2.62)^{* *}$ & \\
\hline Kilifi & $1.27(0.81,1.99)$ & & $1.17(0.76,1.80)$ & & $1.54(1.00,2.38)^{*}$ & & $1.43(0.92,2.21)$ & \\
\hline Kiambu & $0.98(0.63,1.53)$ & & $0.98(0.60,1.59)$ & & $1.84(1.10,3.07)^{*}$ & & $1.89(1.14,3.14)^{*}$ & \\
\hline Kitui & $0.76(0.49,1.19)$ & & $0.77(0.49,1.21)$ & & $1.17(0.75,1.83)$ & & $1.17(0.74,1.87)$ & \\
\hline Nairobi & $0.87(0.56,1.35)$ & & $0.88(0.53,1.47)$ & & $1.42(0.91,2.23)$ & & $1.49(0.91,2.43)$ & \\
\hline Nandi & $1.74(1.12,2.72)^{*}$ & & $1.86(1.18,2.91)^{* *}$ & & $1.43(0.92,2.22)$ & & $1.42(0.91,2.21)$ & \\
\hline Nyamira & $1.02(0.65,1.61)$ & & $1.06(0.67,1.66)$ & & $1.14(0.75,1.74)$ & & $1.16(0.76,1.77)$ & \\
\hline Siaya & $0.79(0.52,1.23)$ & & $0.79(0.51,1.23)$ & & $0.68(0.45,1.01)$ & & $0.66(0.43,1.01)$ & \\
\hline West pokot & $2.97(1.71,5.14)^{* *}$ & & $2.34(1.30,4.22)^{* *}$ & & $2.82(1.36,5.82)^{* *}$ & & $2.43(1.16,5.11)^{*}$ & \\
\hline
\end{tabular}

$p$-value Unadjusted Wald test $p$-value, $p$-value* adjusted Wald test $p$-value, $C l$ Confidence interval, * Significant at $5 \%$ level of significance (los), ** - Significant at $1 \%$ los, Ref. - Reference category

Organization [15] and Gaffield et al. [14] recommends programs not to miss any opportunities to encourage postpartum FP across the continuum of care.

Use of FP during the extended-postpartum period in Kenya has increased from $41 \%$ in 2008 [28] to the current level of 50\% while all method CPR has increased from 46 to $58 \%$ [19]. Our finding of increase in FP use between 0 and 5 months and 6-11 months has been documented previously $[18,29]$. Using family planning calendar data from the Kenya Demographic health survey (DHS) of 2008/9, Winfrey and Kshitiz [29] showed a gradual increase in the use of postpartum FP from $8.7 \%$ in month one to $35.8 \%$ in month 12 postpartum. Using DHS data, Hounton et al. 2015 [30] found increases in use of FP 3-months postpartum in Ethiopia from 5 to $12 \%$, Malawi from 9.5 to $14.2 \%$ and a decrease in Nigeria from 5.9 to $3.8 \%$ from 2008 to 2013 . Though not comparable to Kenya since general CPR is considerably higher than in Ethiopia, Malawi and Nigeria, the reported increase shows potential to increase postpartum FP use while the decrease in Nigeria is a reminder that countries must remain focused on maintaining attained gains.

At the time of the survey, less than half of the women $0-11$ months postpartum (46.5\%) and $64.5 \%$ of women 12 - 23 months postpartum were using modern contraception methods. There is high level of unmet need for FP/C among women 0-11 months postpartum (26.8\%) and among women 12 - 23 months postpartum (18.4\%) which are higher than the national average of $17.5 \%$ in 2014 [19, 24]. Similar high levels of unmet need have been reported in Kenya for limiting at 36 and 48\% for birth spacing among postpartum women [31]. Overall, the unmet need for FP during the extended postpartum period has decreased from $75.2 \%$ in 1998 [32] to $26.8 \%$ in 2018 as documented in this study. There is still room to improve provision of postpartum FP in Kenya. Some of the suggested solutions involve developing strategies to address the inequalities caused by socio-economic factors and the integration of FP with maternal and new born health services, particularly with childbirth in facilities and child immunization [23, 33-35]. Dulli et al. [33] cluster randomized controlled trial in Rwanda showed that integration of FP into immunization services was successful in increasing $\mathrm{mCPR}$ without negatively impacting immunization rates. Hamon et al. [34] found that the integration of FP into routine outreach services could improve acceptability and availability of FP services. The MOMI project demonstrated the potential to shift demand for postpartum care services in the postpartum period by using CHWs [35].

Though interventions to address missed opportunities to reduce unmet contraceptive need would seem straightforward, programs have to navigate potential barriers. Duysburg et al. [17] noted that availability of commodities or services does not translate to postpartum FP use among postpartum women. Ochako et al. [36] found that awareness and knowledge about contraception does not necessarily translate to use among women aged 15-24years, pointing to potential influence of social networks and other barriers. Djellouli et al. [35] also noted the complex interplay between social capital (the relationships between people within the community) and 
Table 5 Bivariate and multivariate analysis of missed FP/C opportunity at the facility among women in the 0-11 months and 12-23 months postpartum periods

\begin{tabular}{|c|c|c|c|c|c|c|c|c|}
\hline \multirow[t]{3}{*}{ Characteristic } & \multicolumn{4}{|c|}{$0-11$ months (extended postpartum) $-N=3016$} & \multicolumn{4}{|c|}{$12-23$ month since last birth $-N=2782$} \\
\hline & \multicolumn{2}{|l|}{ Bivariate analysis } & \multicolumn{2}{|c|}{ Multivariable analysis } & \multicolumn{2}{|l|}{ Bivariate analysis } & \multicolumn{2}{|c|}{ Multivariable analysis } \\
\hline & Odds Ratio $(95 \% \mathrm{Cl})$ & $p$-value & $\begin{array}{l}\text { Adjusted Odds } \\
\text { Ratio }(95 \% \mathrm{Cl})\end{array}$ & $p$-value* & Odds Ratio $(95 \% \mathrm{Cl})$ & $p$-value & $\begin{array}{l}\text { Adjusted Odds } \\
\text { Ratio }(95 \% \mathrm{Cl})\end{array}$ & $p$-value* \\
\hline \multicolumn{9}{|l|}{ Age group } \\
\hline $15-19$ & Ref. & 0.975 & Ref. & 0.791 & Ref. & 0.488 & Ref. & 0.313 \\
\hline $20-24$ & $1.07(0.80,1.42)$ & & $1.14(0.83,1.57)$ & & $1.10(0.79,1.55)$ & & $1.26(0.88,1.81)$ & \\
\hline $25-29$ & $1.03(0.76,1.38)$ & & $1.17(0.81,1.67)$ & & $0.90(0.64,1.29)$ & & $1.03(0.69,1.53)$ & \\
\hline $30-34$ & $1.05(0.76,1.46)$ & & $1.26(0.84,1.89)$ & & $0.91(0.61,1.34)$ & & $1.10(0.68,1.78)$ & \\
\hline $35-39$ & $0.96(0.66,1.41)$ & & $1.05(0.67,1.67)$ & & $0.98(0.65,1.50)$ & & $1.22(0.72,2.07)$ & \\
\hline $40-45$ & $0.83(0.46,1.51)$ & & $0.87(0.43,1.79)$ & & $1.21(0.68,2.17)$ & & $1.55(0.82,2.96)$ & \\
\hline $45-49$ & $0.83(0.25,2.72)$ & & $0.68(0.20,2.26)$ & & $0.70(0.30,1.65)$ & & $0.71(0.27,1.89)$ & \\
\hline \multicolumn{9}{|l|}{ Marital Status } \\
\hline Never Married & Ref. & 0.228 & Ref. & 0.656 & Ref. & 0.598 & Ref. & 0.641 \\
\hline Married/In a union & $0.88(0.69,1.11)$ & & $0.97(0.73,1.30)$ & & $0.95(0.72,1.26)$ & & $0.95(0.67,1.35)$ & \\
\hline Widowed/Divorced & $0.63(0.36,1.09)$ & & $0.76(0.41,1.40)$ & & $1.15(0.73,1.81)$ & & $1.18(0.71,1.94)$ & \\
\hline \multicolumn{9}{|l|}{ Residence } \\
\hline Urban & Ref. & 0.171 & Ref. & 0.930 & Ref. & 0.188 & Ref. & 0.676 \\
\hline Rural & $1.19(0.93,1.52)$ & & $1.01(0.75,1.36)$ & & $0.84(0.64,1.09)$ & & $0.94(0.71,1.25)$ & \\
\hline \multicolumn{9}{|l|}{ Education } \\
\hline No Education & Ref. & 0.344 & Ref. & 0.393 & Ref. & 0.863 & Ref. & 0.590 \\
\hline Primary & $0.61(0.37,0.99)^{*}$ & & $0.67(0.43,1.04)$ & & $0.99(0.57,1.73)$ & & $1.02(0.59,1.78)$ & \\
\hline $\begin{array}{l}\text { Technical/voca- } \\
\text { tional }\end{array}$ & $0.56(0.26,1.20)$ & & $0.61(0.30,1.22)$ & & $0.71(0.31,1.60)$ & & $0.60(0.25,1.42)$ & \\
\hline Secondary & $0.58(0.35,0.97)^{*}$ & & $0.63(0.39,1.02)$ & & $0.96(0.53,1.73)$ & & $0.93(0.51,1.70)$ & \\
\hline Higher & $0.58(0.33,1.01)$ & & $0.57(0.32,1.00)^{*}$ & & $0.92(0.50,1.70)$ & & $0.94(0.51,1.72)$ & \\
\hline \multicolumn{9}{|l|}{ Wealth Quintile } \\
\hline Lowest & Ref. & 0.196 & Ref. & 0.139 & Ref. & 0.952 & Ref. & 0.998 \\
\hline Lower & $0.74(0.56,0.98)^{*}$ & & $0.81(0.61,1.07)$ & & $0.91(0.69,1.20)$ & & $0.96(0.73,1.27)$ & \\
\hline Middle & $0.71(0.53,0.96)^{*}$ & & $0.90(0.66,1.22)$ & & $0.95(0.71,1.28)$ & & $1.00(0.75,1.33)$ & \\
\hline Higher & $0.72(0.54,0.97)^{*}$ & & $1.02(0.71,1.46)$ & & $1.01(0.73,1.40)$ & & $0.95(0.68,1.34)$ & \\
\hline Highest & $0.78(0.54,1.12)$ & & $1.29(0.82,2.03)$ & & $1.00(0.67,1.50)$ & & $0.97(0.61,1.55)$ & \\
\hline \multicolumn{9}{|l|}{ Parity } \\
\hline $1-2$ & Ref. & 0.039 & Ref. & 0.019 & Ref. & 0.194 & Ref. & 0.523 \\
\hline $3-4$ & $0.78(0.63,0.96)^{*}$ & & $0.71(0.55,0.92)^{* *}$ & & $0.84(0.70,1.02)$ & & $0.87(0.68,1.12)$ & \\
\hline $5+$ & $1.03(0.81,1.32)$ & & $0.92(0.65,1.30)$ & & $0.88(0.68,1.13)$ & & $0.85(0.59,1.21)$ & \\
\hline \multicolumn{9}{|l|}{ Sexually active } \\
\hline No & Ref. & 0.762 & Ref. & 0.952 & Ref. & 0.588 & Ref. & 0.533 \\
\hline Yes & $0.97(0.80,1.18)$ & & $1.01(0.81,1.25)$ & & $0.94(0.75,1.18)$ & & $1.10(0.82,1.46)$ & \\
\hline \multicolumn{9}{|l|}{ Data collection round } \\
\hline Jun/Jul 2014 & Ref. & 0.021 & Ref. & 0.004 & Ref. & 0.009 & Ref. & 0.011 \\
\hline Nov/Dec 2014 & $0.73(0.47,1.12)$ & & $0.70(0.46,1.07)$ & & $0.77(0.47,1.27)$ & & $0.77(0.47,1.27)$ & \\
\hline Jun/Jul 2015 & $1.00(0.64,1.58)$ & & $1.03(0.67,1.60)$ & & $0.55(0.35,0.87)$ & & $0.54(0.35,0.85)^{* *}$ & \\
\hline Nov/Dec 2015 & $0.62(0.38,1.01)$ & & $0.61(0.39,0.97)^{*}$ & & $0.46(0.28,0.77)$ & & $0.45(0.27,0.75)^{* *}$ & \\
\hline Nov/Dec 2016 & $0.62(0.41,0.96)^{*}$ & & $0.56(0.36,0.87)^{*}$ & & $0.56(0.37,0.87)$ & & $0.61(0.39,0.96)^{*}$ & \\
\hline Nov/Dec 2017 & $0.77(0.50,1.18)$ & & $0.72(0.47,1.11)$ & & $0.51(0.33,0.78)$ & & $0.50(0.32,0.78)^{* *}$ & \\
\hline Nov/Dec 2018 & $0.53(0.35,0.80)^{* *}$ & & $0.49(0.33,0.74)^{* *}$ & & $0.45(0.29,0.71)$ & & $0.47(0.29,0.76)^{* *}$ & \\
\hline
\end{tabular}


Table 5 (continued)

\begin{tabular}{|c|c|c|c|c|c|c|c|c|}
\hline \multirow[t]{3}{*}{ Characteristic } & \multicolumn{4}{|c|}{0 - 11 months (extended postpartum) $-N=3016$} & \multicolumn{4}{|c|}{$12-23$ month since last birth $-N=2782$} \\
\hline & \multicolumn{2}{|l|}{ Bivariate analysis } & \multicolumn{2}{|c|}{ Multivariable analysis } & \multicolumn{2}{|l|}{ Bivariate analysis } & \multicolumn{2}{|c|}{ Multivariable analysis } \\
\hline & Odds Ratio $(95 \% \mathrm{Cl})$ & $p$-value & $\begin{array}{l}\text { Adjusted Odds } \\
\text { Ratio }(95 \% \mathrm{Cl})\end{array}$ & $p$-value* & Odds Ratio $(95 \% \mathrm{Cl})$ & $p$-value & $\begin{array}{l}\text { Adjusted Odds } \\
\text { Ratio }(95 \% \mathrm{Cl})\end{array}$ & $p$-value* \\
\hline \multicolumn{9}{|l|}{ County } \\
\hline Bungoma & Ref. & $<0.001$ & Ref. & $<0.001$ & Ref. & 0.006 & Ref. & 0.011 \\
\hline Kakamega & $1.15(0.66,2.00)$ & & $1.38(0.78,2.46)$ & & $0.76(0.38,1.52)$ & & $0.85(0.42,1.7)$ & \\
\hline Kericho & $2.12(1.30,3.45)^{* *}$ & & $2.04(1.25,3.33)^{* *}$ & & $2.45(1.54,3.90)$ & & $2.50(1.56,4.01)^{* *}$ & \\
\hline Kilifi & $1.76(1.03,3.00)^{*}$ & & $1.55(0.94,2.56)$ & & $1.79(1.09,2.95)$ & & $1.79(1.08,2.98)^{*}$ & \\
\hline Kiambu & $1.13(0.66,1.95)$ & & $0.96(0.54,1.71)$ & & $1.72(0.91,3.25)$ & & $1.60(0.85,3.00)$ & \\
\hline Kitui & $0.84(0.50,1.42)$ & & $0.82(0.48,1.40)$ & & $1.33(0.78,2.27)$ & & $1.40(0.80,2.47)$ & \\
\hline Nairobi & $1.14(0.68,1.90)$ & & $0.89(0.50,1.58)$ & & $1.93(1.16,3.20)$ & & $1.80(1.04,3.13)^{*}$ & \\
\hline Nandi & $2.81(1.70,4.62)^{* *}$ & & $2.97(1.79,4.94)^{* *}$ & & $2.00(1.22,3.26)$ & & $2.07(1.25,3.43)^{* *}$ & \\
\hline Nyamira & $1.29(0.75,2.21)$ & & $1.34(0.78,2.29)$ & & $1.34(0.81,2.20)$ & & $1.33(0.80,2.21)$ & \\
\hline Siaya & $1.45(0.88,2.38)$ & & $1.46(0.88,2.43)$ & & $1.46(0.94,2.24)$ & & $1.43(0.91,2.27)$ & \\
\hline West Pokot & $2.62(1.24,5.56)^{*}$ & & $2.40(1.12,5.15)^{*}$ & & $2.10(0.92,4.77)$ & & $2.42(1.04,5.64)^{*}$ & \\
\hline
\end{tabular}

$p$-value - Unadjusted Wald test $p$-value, $p$-value* - adjusted Wald test $p$-value, $\mathrm{Cl}$ - Confidence interval, ${ }^{*}$ - Significant at $5 \%$ level of significance (los), ${ }^{* *}$ - Significant at $1 \%$ los, Ref. - Reference category

the development of bonding social capital to become a community norm allowing women to seek postpartum care services. A multipronged approach will be necessary if FP programs are going to capitalize on missed opportunities to reduce unmet contraceptive need. Among the many options to consider will be tapping into the potential of CHWs to be agents of social change and promote postpartum FP use [35] and integration of postpartum FP into other services where capacity exists to ensure quality of primary services are not compromised [33].

There are some limitations which need to be considered when interpreting the data. By use of cross-sectional design, we were limited in our ability to examine whether reported missed opportunities resulted in unintended pregnancies. There is a risk of recall bias, particularly for women who delivered at the beginning of the 2-year reference period. Since only individual-level factors were examined in this study, it is possible that post-partum FP practice is influenced by community-level factors that were not measured. For example, community norms about contraceptive use may positively or negatively influence an individual's contraceptive behaviours. Additionally, being a household survey, there are no facility data which would have allowed determination of integration of FP and reproductive health services. There are strengths to this survey which include inclusion of a large sample of women, use of data collectors without medical training to reduce bias and real-time data collection with sufficient controls for quality assurance. In addition, pooled data from seven-rounds of survey were included. Necessary statistical adjustment including svyset command in Stata designating the round number as a stratum were used to take care of clustering by round since the women included were not independently sampled.

\section{Conclusion}

In conclusion, given the vulnerabilities of women during the extended postpartum period, programs specifically addressing the needs of postpartum women need to be strengthened. Though Kenya is making progress meeting the needs of women who desire to use family planning, there is need for implementing innovative interventions to address missed opportunities during the extended postpartum period. Strengthening health systems, integrating service delivery for the postpartum period and promoting demand for postpartum contraception (PPC) through community interventions offer potential for success. Similarly, the findings regarding high rates of unmet need, which are consistent across different locations in Kenya, point to the need for further research for interventions to improve access to family planning services. Using a longitudinal study will be useful to understand the context of the contacts as well as the quality the women have with $\mathrm{HCW}$ and $\mathrm{CHW}$ to maximize use of these opportunities to increase $\mathrm{mCPR}$.

\section{Abbreviations}

AOR: Adjusted Odds Ratio; CHW: Community Health workers; DHS: Demographic and Health Survey; FP/C: Family Planning/Contraception; HCW: Health Care Workers; mCPR: Modern Contraceptive Prevalence Rate; PMA2020: Performance Monitoring and Accountability 2020; PPC: Postpartum Care. 


\section{Supplementary Information}

The online version contains supplementary material available at https://doi. org/10.1186/s12889-022-12623-0.

Additional file 1: Supplemental materials. Table 1. Missed opportunities for FP/C counselling, FP use and unmet need for FP. Figure 1. Pictorial representation of missed opportunity definition (All participants). Figure 2. Pictorial representation of missed opportunity definition (Women in the extended postpartum period). Figure 3. Pictorial representation of missed opportunity definition (Women 12-23 months post-delivery).

\section{Acknowledgements}

We would like to thank Philip Anglewicz from Johns Hopkins University for the ideas shared during the paper writing workshop and Nga'ng'a J from Kenya National Bureau of Statistics for all the technical support in confirmation of applied weights.

\section{Authors' contributions}

MNT and PBG proposed the idea, wrote the analysis plan, wrote the manuscript and supervised all the statistical analysis. MW analyzed the data. AT, LAZ, SR, MT and SA reviewed and critically revised the manuscript. All authors read and approved the final manuscript.

\section{Funding}

This work was supported by Bill \& Melinda Gates Foundation grant number [xxx].

The funding body had no role in the design of the study, data collection, analysis, and interpretation of data and in writing the manuscript.

\section{Availability of data and materials}

The datasets generated during the study are publicly available from the PMA website (https://www.pma2020.org/request-access-to-datasets),

\section{Declarations}

\section{Ethics approval and consent to participate}

Written informed consent was obtained for all participants and if subject was under 18 years, from a parent and/or legal guardian. Minors also gave assent. Ethical approval was provided by Kenyatta National Hospital/University of Nairobi ethical review committee (REF: P15/01/2014) and National Commission for Science, Technology and Innovation (REF: NACOSTI/P/14/0813/1676).

\section{Consent for publication}

Not applicable.

\section{Competing interests}

The authors declare that they have no competing interests.

\section{Author details}

${ }^{1}$ International Centre for Reproductive Health, Mombasa, Kenya. ${ }^{2}$ Technical University of Mombasa, Mombasa, Kenya. ${ }^{3}$ Department of Population, Family and Reproductive Health, Johns Hopkins Bloomberg school of Public Health, Baltimore, MD, USA. ${ }^{4}$ Aga Khan University, Nairobi, Kenya.

Received: 30 December 2020 Accepted: 18 January 2022 Published online: 08 February 2022

\section{References}

1. Black RE, Levin C, Walker N, Chou D, Liu L, Temmerman M. Reproductive, maternal, newborn, and child health: key messages from Disease Control Priorities 3rd Edition. Lancet. 2016. https://doi.org/10.1016/S01406736(16)00738-8 Accessed Nov 2020.

2. Temmerman M, Khosla R, Laski L, Mathews Z, Say L. Women's health priorities and interventions. BMJ. 2015;351:h4147. https://doi.org/10.1136/ bmj.h4147.
3. Kozuki N, Walker N. Exploring the association between short/long preceding birth intervals and child mortality: Using reference birth interval children of the same mother as comparison. BMC Public Health. 2013;13. https://doi.org/10.1186/1471-2458-13-S3-S6

4. Ahmed S, Li Q, Liu L, Tsui AO. Maternal deaths averted by contraceptive use: An analysis of 172 countries. Lancet. 2012;380:111-25. https://doi. org/10.1016/S0140-6736(12)60478-4.

5. Canning D, Schultz TP. The economic consequences of reproductive health and family planning. Lancet. 2012;380:165-71. https://doi.org/10. 1016/S0140-6736(12)60827-7.

6. Sully EA, Biddlecom A, Darroch JE, Riley T, Ashford LS, Lince-Deroche N, et al. Adding it up: investing in sexual and reproductive health 2019. New York: Guttmacher Institute; 2020. https://www.guttmacher.org/report/ adding-it-upinvesting-in-sexual-reproductive-health-2019. Accessed Nov 2020

7. Conde-Agudelo A, Rosas-Bermúdez A, Kafury-Goeta AC. Birth spacing and risk of adverse perinatal outcomes: a meta-analysis. J Am Med Assoc. 2006:295:1809-23. https://doi.org/10.1001/jama.295.15.1809.

8. Rutstein SO. Further evidence of the effects of preceding birth intervals on neonatal, infant, and under-five-years mortality and nutritional status in developing countries. Evid Demograph Health Surveys. 2008; https:// dhsprogram.com/pubs/pdf/WP41/WP41.pdf. Accessed Nov 2020.

9. Grisaru-Granovsky S, Gordon ES, Haklai Z, Samueloff A, Schimmel MM. Effect of interpregnancy interval on adverse perinatal outcomes - a national study. Contraception. 2009;80:512-8. https://doi.org/10.1016/j. contraception.2009.06.006.

10. Defranco EA, Seske LM, Greenberg JM, Muglia LJ. Influence of interpregnancy interval on neonatal morbidity. Am J Obstet Gynecol. 2015:212:386.e1-9. https://doi.org/10.1016/j.ajog.2014.11.017.

11. World Health Organization (WHO). Report of a WHO Technical Consultation on Birth Spacing. vol. 13: WHO 2007. p. 2005. https://apps.who.int/ iris/bitstream/handle/10665/69855/WHO_RHR_07.1_eng.pdf?seque nce $=1 \& u a=1$. Accessed Nov 2020

12. Chersich MF, Kley N, Luchters SMF, Njeru C, Yard E, Othigo MJ, et al. Maternal morbidity in the first year after childbirth in Mombasa Kenya; a needs assessment. BMC Pregnancy Childbirth. 2009;9:51. https://doi.org/ 10.1186/1471-2393-9-51.

13. Zhu BP, Haines KM, Le T, McGrath-Miller K, Boulton ML. Effect of the interval between pregnancies on perinatal outcomes among white and black women. Am J Obstet Gynecol. 2001;185:1403-10. https://doi.org/ 10.1067/mob.2001.118307.

14. Gaffield ME, Egan S, Temmerman M. It's about time: WHO and partners release programming strategies for postpartum family planning. Glob Health Sci Pract. 2014;2(1):4-9. https://doi.org/10.9745/GHSP-D-13-00156 eCollection 2014 Feb.

15. Cleland J, Conde-Agudelo A, Peterson H, Ross J, Tsui A. Contraception and health. Lancet. 2012;380:149-56. https://doi.org/10.1016/S01406736(12)60609-6.

16. Conde-Agudelo A, Rosas-Bermudez A, Castaño F, Norton MH. Effects of birth spacing on maternal, perinatal, infant, and child health: a systematic review of causal mechanisms. vol. 43; 2012. https://doi.org/10.1111/j. 1728-4465.2012.00308.x.

17. Duysburgh E, Kerstens B, Kouanda S, Kaboré PC, Belemsaga Yugbare D, Gichangi $P$, et al. Opportunities to improve postpartum care for mothers and infants: Design of context-specific packages of postpartum interventions in rural districts in four sub-Saharan African countries. BMC Pregnancy Childbirth. 2015;15. https://doi.org/10.1186/s12884-015-0562-8.

18. William W, Rakesh K. Use of Family Planning in the Postpartum Period. DHS Comparative Reports No. 36. Rockville: ICF International. https:// dhsprogram.com/pubs/pdf/CR36/CR36.pdf. Accessed Nov 2020

19. Kenya National Bureau of Statistics (KNBS). Kenya demographic and health survey 2014. Chapter 9. Calverton: KNBS and ICF Macro; 2015. https://www.dhsprogram.com/pubs/pdf/FR308/FR308.pdf. Accessed Nov 2020

20. Botfield JR, Tulloch M, Contziu H, Phipps H, Bateson D, Wright SM, et al. Contraception provision in the postpartum period: Knowledge, views and practices of midwives. Women Birth. 2021;34(1):e1-6. https://doi.org/ 10.1016/j.wombi.2020.07.013.

21. Yugbaré Belemsaga D, Bado A, Goujon A, Duysburgh E, Degomme O, Kouanda S, et al. A cross-sectional mixed study of the opportunity to improve maternal postpartum care in reproductive, maternal, newborn, 
and child health services in the Kaya health district of Burkina Faso. Int J Gynecol Obstet. 2016;135:S20-6. https://doi.org/10.1016/j.ijgo.2016.08. 005.

22. Dynes MM, Bernstein E, Morof D, Kelly L, Ruiz A, Mongo W, et al. Client and provider factors associated with integration of family planning services among maternal and reproductive health clients in Kigoma Region, Tanzania: a cross-sectional study, April-July 2016. Reprod Health. 2018;15. https://doi.org/10.1186/s12978-018-0593-5.

23. Mackenzie D, Pfitzer A, Maly C, Waka C, Singh G, Sanyal A. Postpartum family planning integration with maternal, newborn and child health services: A cross-sectional analysis of client flow patterns in India and Kenya. BMJ Open. 2018;8. https://doi.org/10.1136/bmjopen-2017-018580.

24. Moore Z, Pfitzer A, Gubin R, Charurat E, Elliott L, Croft T. Missed opportunities for family planning: An analysis of pregnancy risk and contraceptive method use among postpartum women in 21 low- and middle-income countries. Contraception. 2015;92:31-9. https://doi.org/10.1016/j.contr aception.2015.03.007.

25. Zimmerman L, Olson H, Tsui A, Radloff S. PMA2020: Rapid Turn-Around Survey Data to Monitor Family Planning Service and Practice in Ten Countries. Stud Fam Plan. 2017:48:293-303. https://doi.org/10.1111/sifp.12031.

26. Jackson E, Glasier A. Return of ovulation and menses in postpartum nonlactating women: A systematic review. Obstet Gynecol. 2011;117:657-62. https://doi.org/10.1097/AOG.0b013e31820ce18c.

27. Gichangi P, Waithaka M, Thiongo M, Agwanda A, Radloff S, Tsui A, et al. Demand satisfied by modern contraceptive among married women of reproductive age in Kenya. PLoS One. 2021;16(4):e0248393. https://doi. org/10.1371/journal.pone.0248393.

28. Gebreselassie T, Rutstein SO, Mishra V. Contraceptive use, breastfeeding, amenorrhea and abstinence during the postpartum period: an analysis of four countries. https://dhsprogram.com/publications/publication-as14analytical-studies.cfm. Accessed Nov 2020

29. Hounton S, Winfrey W, Barros AJD, Askew I. Patterns and trends of postpartum family planning in Ethiopia, Malawi, and Nigeria: Evidence of missed opportunities for integration. Glob Health Action. 2015;8. https:// doi.org/10.3402/gha.v8.29738.

30. Winfrey W, Kshitiz R. Use of family planning in the postpartum period. DHS Comparative Report No. 36. Rockville: ICF International, https:// dhsprogram.com/pubs/pdf/CR36/CR36.pdf, Accessed Nov 2020; 2014.

31. Pasha O, Goudar SS, Patel A, Garces A, Esamai F, Chomba E, et al. Postpartum contraceptive use and unmet need for family planning in five low-income countries. Reprod Health. 2015;12. https://doi.org/10.1186/ 1742-4755-12-S2-S11.

32. Ross JA, Winfrey WL. Contraceptive use, intention to use and unmet need during the extended postpartum period. Int Fam Plan Perspect. 2001;27:20-7. https://doi.org/10.2307/2673801.

33. Dulli LS, Eichleay M, Rademacher K, Sortijas S, Nsengiyumva T. Meeting postpartum women's family planning needs through integrated family planning and immunization services: Results of a cluster-randomized controlled trial in Rwanda. Glob Heal Sci Pract. 2016;4:73-86. https://doi. org/10.9745/GHSP-D-15-00291.

34. Hamon JK, Krishnaratne S, Hoyt J, Kambanje M, Pryor S, Webster J. Integrated delivery of family planning and childhood immunisation services in routine outreach clinics: findings from a realist evaluation in Malawi. BMC Health Serv Res. 2020;20(1):777. https://doi.org/10.1186/ s12913-020-05571-1.

35. Djellouli N, Mann S, Nambiar B, Meireles P, Miranda D, Barros H, et al. Improving postpartum care delivery and uptake by implementing context-specific interventions in four countries in Africa: A realist evaluation of the missed opportunities in maternal and infant health (MOMI) project. BMJ Glob Health. 2017;2. https://doi.org/10.1136/bmjgh-2017-000408.

36. Ochako R, Mbondo M, Aloo S, Kaimenyi S, Thompson R, Temmerman M, et al. Barriers to modern contraceptive methods uptake among young women in Kenya: A qualitative study Global Health. BMC Public Health. 2015;15:118. https://doi.org/10.1186/s12889-015-1483-1.

\section{Publisher's Note}

Springer Nature remains neutral with regard to jurisdictional claims in published maps and institutional affiliations.
Ready to submit your research? Choose BMC and benefit from:

- fast, convenient online submission

- thorough peer review by experienced researchers in your field

- rapid publication on acceptance

- support for research data, including large and complex data types

- gold Open Access which fosters wider collaboration and increased citations

- maximum visibility for your research: over $100 \mathrm{M}$ website views per year

At BMC, research is always in progress.

Learn more biomedcentral.com/submissions 